\title{
Robotic urologic surgery complications
}

\author{
Erdem Koc, Abdullah Erdem Canda \\ Department of Urology, Ankara Ataturk Training and Research Hospital, Ankara 06800, Turkey.
}

Correspondence to: Dr. Erdem Koc, Department of Urology, Ankara Atatürk Training and Research Hospital, Bilkent ST, No.1, Çankaya, Ankara 06800,Turkey. E-mail: drerdemkoc@gmail.com

How to cite this article: Koc E, Canda AE. Robotic urologic surgery complications. Mini-invasive Surg 2018;2:7.

http://dx.doi.org/10.20517/2574-1225.2017.33

Received: 3 Aug 2017 First Decision: 24 Feb 2018 Revised: 6 Mar 2018 Accepted: 16 Mar 2018 Published: 16 Apr 2018

Science Editor: Charles F. Bellows, Yasar Ozgok Copy Editor: Jun-Yao Li Production Editor: Huan-Liang Wu

\begin{abstract}
Robot-assisted surgery is a commonly performed procedure in the recent urological approach. The scientific data that reveal the complication rates also tend to increase by the rising popularity of the robot-assisted surgeries in the treatment of urological cancers. Patient characteristics, nature of the cancer and learning curve of the surgeon are the determinant factors of the complication rates. Nevertheless, robot-assisted surgical techniques are safer with acceptable morbidity and mortality rates as compared to open surgical methods. In urology practice, robotic surgery is most commonly performed in the treatment of prostate cancer. Thus, this review subjected to reveal the commonly seen and the serious complications of robot-assisted radical prostatectomy, and their prevention and management.
\end{abstract}

Keywords: Urology, robot-assisted surgery, prostatectomy, complication

\section{INTRODUCTION}

Robot-assisted surgery is a minimally invasive procedure with a rising popularity worldwide. In urology practice, robotic surgery is most commonly performed in treatment of prostate cancer (PCa). As the relatively high morbidity and mortality rates of open radical prostatectomy (ORP) are considered, robotic surgery becomes the preferred method in the treatment of PCa with distinct advantages in comparison with open surgery in terms of functional and oncologic outcomes and complication rates.

The complication rates are reported following ORP by many authors. However, uniformity does not exist in data documentation and reporting methods of the complications resulting in incomplete data collection and problematic comparisons among different surgical approaches and different institutional series.

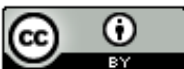

(C) The Author(s) 2018. Open Access This article is licensed under a Creative Commons Attribution 4.0 International License (https://creativecommons.org/licenses/by/4.0/), which permits unrestricted use sharing, adaptation, distribution and reproduction in any medium or format, for any purpose, even commercially, as long as you give appropriate credit to the original author(s) and the source, provide a link to the Creative Commons license, and indicate if changes were made.

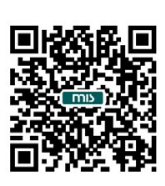


Clavien-Dindo classification has been used as a standardized classification in general surgical literature ${ }^{[1]}$. Martin et al. ${ }^{[2]}$ proposed a report in 2002, to standardize the classification criteria that should be incorporated into surgical complication reports including definitions of general and procedure-specific complications, data accrual, and follow-up period, inclusion of length of stay and outpatient information, identification of mortality and morbidity rates, application of a grading system for complications, and analysis of risk stratification. However, they reported hepatectomy, pancreatectomy, and esophagectomy as specific examples ${ }^{[2]}$. Donat ${ }^{[3]}$ modified these criteria in 2007 , to include procedure-specific complications concerning urology such as inadvertent visceral injury, bleeding and transfusion rates, urine leakage, and lymphocele formation.

This paper aimed to present the commonly seen and serious surgical complications of robot-assisted radical prostatectomy (RARP) as the most frequently performed robot-assisted procedure in urology practice, and their prevention and management.

\section{METHODS}

A systematic search was performed in PubMed database. Studies that referred to RARP complications are detected and evaluated. Papers were identified through database screening and after initial screening. Only the full text available articles in English, published between 2000 and 2017 were included. The keywords comprised "urology, robot-assisted surgery, prostatectomy, complication". Most commonly seen robotassisted surgery complications and radical prostatectomy complications were individually researched. As the result, an overview of most commonly seen RARP-related complication topics that should be useful in robotic urology.

\section{RARP COMPLICATIONS}

The number of robot-assisted procedures increases gradually in urology practice. In USA, 67\% of prostatectomies have been performed robotically ${ }^{[4]}$. Even though, open radical cystectomy has higher complication rates compared to $\mathrm{RARP}^{[5]}$, a great number of surgeons have been in their learning curve in terms of robotic urologic surgery practice thus may explain the most of the robotic surgery complications.

\section{Rectum and bowel injuries}

Rectal injury is a rare but devastating complication of RARP. In a recent systematic review and metaanalysis, the incidence of rectal injury was reported as low as $0.2 \%{ }^{[6]}$. Patient history of prostate or rectal surgery, hormonal therapy, radiotherapy, periprostatic fibrosis and infection constitute the risk factors for rectal injury. Besides, the ill-defined plane between the rectum and prostate, and the difficulty in dissection of locally advanced tumors also may be responsible for rectal injuries ${ }^{[7,8]}$.

Novara et al. ${ }^{[9]}$ analyzed 415 clinically localized PCa patients who underwent RARP. Five cases were complicated with rectal injury, and all of them were detected intra-operatively (1.5\%). The lesions were sutured the lesions immediately in 2 or 3 planes, and patients used broad-spectrum antibiotics for 7 days and took liquid diet for 4 days. The bladder catheter was removed after a median of 9 days. The postoperative course was uneventful for all cases ${ }^{[9]}$.

Wedmid et al ${ }^{[10]}$ reported 11 rectal injury cases out of a totally 6650 RARP patients. Rectal injury was recognized in 8 of 11 patients intra-operatively and repaired in the same session. Primary repair was performed in 7 cases by the robotic surgeon. Diverting colostomy with primary repair was performed in only 1 patient. Two and three-layer closure was applied for the full thickness lacerations ${ }^{[10]}$. 
Hung et al. ${ }^{[11]}$ detected the bowel injury rate as $1.04 \%$ in total 288 RARP patients. Before the RARP, all of the patients were received transurethral resection of the prostate. Rectal injury was detected in 2 cases and sigmoid colon in 1. Sigmoid colon injury was unrecognized during the course of RARP and therefore could not be repaired intra-operatively. Peritonitis leading to bowel resection and colostomy was the warning symptom in this case. In 1 patient with rectal injury, late recto-urethral fistula was detected. Colostomy, prolonged urethral catheterization, and perineal repair were performed, and colostomy was taken down subsequently after recovery.

Ileo-colonic injuries primarily present postoperatively with abdominal distention, ileus and absent peritoneal signs. Nowadays, primary repair is preferred without colostomy in most cases. Typically 2-layer closure with 2/0 polyglactin is used for repair and the compliance of sutures are tested by air insufflation through the rectum. Prolonged catheterization is recommended for a mean of 14 days. Failure to recognize and immediately treat a bowel injury may result in a high mortality rate up to $3 \%$ and high morbidity ${ }^{[12]}$. However, careful and sharp dissection by the assistance to hold the rectum posteriorly with a suction irrigation tip, and avoiding entry into the perirectal fat prevent rectal injury in $\mathrm{RARP}^{[11]}$.

\section{Urine leakage}

Urine leakage is a prevalent and low-grade surgical complication with the rate of $1.8 \%{ }^{[6]}$. Increased drain output is the most common sign. Drain creatinine level is used to detect the type of the fluid.

Jacobsen et al. ${ }^{[13]}$ reported the rate of the urinary leakage as $2.1 \%$ in their study including 236 RARP patients. Age, smoking, diabetes mellitus, hypertension and prostate volume were not found to be associated with anastomotic leakage. However, obesity and excessive bleeding were associated with decreased visibility of the bladder neck, hampering suture placement in urethro-vesical anastomosis ${ }^{[14]}$. As a surgical factor, non-eversion of the mucosa was suggested for tighter anastomosis instead of eversion ${ }^{[15]}$.

The origin of urine leakage may also be the ureteral injury as well as the urethro-vesical anastomosis. Urgent management is needed in urethral injury. Cystography should be used to detect the origin of the leakage. Prolonged catheterization is recommended for a mean of 10 to 14 days. Cystography should be repeated in case of high volume leakage. If the leakage is observed as minimal, catheter should be removed one week later with no need for cystography ${ }^{[16,17]}$.

Uroperitoneum is the most serious short-term complication of the urine leakage, and may lead to peritonitis, deterioration in renal functions and ileus. Before the reoperation decision, pelvic drain or nephrostomy tube can be placed ${ }^{[14]}$.

\section{Ureteric injuries}

Most of the ureteric injuries can be detected in postoperative period. The incidence varies between $0.1 \%$ and $0.3 \%$ during RARP ${ }^{[18]}$. The injury may be at several different levels of the ureter. The distal ureter injury risk increases while performing Montsouris approach ${ }^{[19]}$. In patients with transurethral resection of the prostate (TUR-P) history, the ureteral orifice may not be in its typical location. Attention must be at the highest level to avoid cutting closely to the ureteral orifices during the dorsal dissection of the bladder, especially in post-TUR-P cases.

The ureter can be mistaken in an extremely lateral dissection to find vas deferens, and therefore may be ligated, transected or injured thermally. In prevention, tubular structures as the vas deferens must be divided after being sure of its exact identity. Vas deferens converges in the midline from lateral to medial in differentiation from ureter. 
Medial ureteral injury usually occurs during the extended pelvic lymph node dissection (PLND) at the level of the iliac vessels. Ureters should be visualized clearly to avoid any type of injury. The safety distance increases by pulling the ureter away with the help of robotic arms.

Any type of ureteral injury can be corrected during the course of robotic surgery. In non-transecting injuries, ureteral stent should be placed through the bladder opening. Repair with 5/0 Monocryl (Ethicon) suture after stent placement allows the correction of partially or fully transected ureters. Transverse closure of longitudinal defects prevents narrowing of the ureter. In case of wide injury in the ureter or ureteral orifice, ureteral reimplantation may the treatment choice ${ }^{[20]}$.

\section{Bleeding}

Postoperative bleeding rate was reported as $0.5 \%-2.0 \%$ according to various definitions after radical prostatectomy. Most papers reported blood loss between 100 and $300 \mathrm{~mL}^{[21-26]}$.

It is possible to cope with the bleeding that occurs during the operation. However, bleeds that are not seen due to the increased intra-abdominal pressure may cause bleeding afterwards. Bleeding is most often seen at the dorsal vein complex, lateral pedicles and port sites. Therefore, the intra-abdominal pressure should be reduced after the operation even if it is expected to decrease for a while, and then the hemostasis should be repeated. After the ports are removed, it should be checked whether any bleeds exist arising from the port sites.

In a case report, Lorenzo et al. ${ }^{[27]}$ reported a small perforation at iliac vein during their PLND performance, and they denoted that bleeding was stopped by the bipolar forceps and $5 \mathrm{~mm}$ metal clipping.

In a study consisted of 1000 RARP patients, Ahmed et al. ${ }^{[28]}$ reported that blood transfusion was needed for $15(1.5 \%)$ patients for approximately 4.4 units per patient. The transfusion indication was based on tachycardia and hypotension except 6 patients who needed transfusion due to significant cardiac disease history to maintain hematocrit level $>30 \%{ }^{[28]}$.

Patel et al. ${ }^{[29]}$ indicated complication rates as $4.3 \%$ in a series of 1500 patients including 8 hemorrhages, 5 of which required blood transfusion due to decrease in hemoglobin levels at postoperative 5th hour. Bleeding stopped at post-operative 3rd-4th days and hemoglobin levels stabilized. All patients were treated successfully without surgical exploration ${ }^{[29]}$. Controversy, Murphy et al ${ }^{[30]}$ reported complication rates as high as $15.7 \%$ in their 400 patient series in which 1 of the 15 complicated cases (3.75\% of total) were reoperated due to bleeding.

Postoperative hematomas may also be seen but often resolve spontaneously. Fischer et al. ${ }^{[31]}$ also reported urinary retention due to retrovesical hematoma as a rarely observed complication that resolved spontaneously.

Tasci et al ${ }^{[32]}$ reported a total of 5 postoperative transfusion-requiring bleedings among their 317 patient series of RARP. In postoperative 5th hour, hemoglobin levels were found as reduced in these 5 cases. However, vital findings and general status were stable. Subsequent hemoglobin and hematocrit levels continued to fall. Blood and the blood products were transfused. In postoperative 2 nd day, ecchymosis was detected on posterior and lateral walls of abdomen, scrotum, and spread up to the legs. Hemorrhage was minimal in abdomen drainage and no bleeding was detected in the abdomen in computed tomography during the follow-up period. However, there was severe hemorrhage sourcing from abdominal walls. Nevertheless, bleeding stopped on the 3rd or 4th day without surgical exploration, and hemoglobin became stable $^{[32]}$. 
RARP has extremely low complication rates in terms of postoperative bleeding. This success may be the result of elevated intra-abdominal pressure by $\mathrm{CO}_{2}$ insufflation, excellent vision quality and thin dissection opportunities.

\section{Veress needle injuries}

In Veress technique, the needle should be placed at the horizontal plane at a $45^{\circ}$ angle for umbilical access. In obese patients, the needle should be placed at $45^{\circ}$ to $90^{\circ}$ angle to prevent vascular injury.

A meta-analysis revealed that vascular injury might be seen at a mean rate of $0.044 \%$ during laparoscopic access $^{[33]}$. In management of the vascular injuries related with the Veress needle, we should target to the specific situation. If a nonexpanding small hematoma exists, it may be outlined by clips and monitored during the course of the surgery. If the hematoma is found as expanded in reinspection at the end of the surgery, the hematoma should be opened to explore the bleeding site.

\section{Trocar injury}

The major vascular injury incidence related with Veress needles and trocars is approximately $0.1 \%$. A study carried out by US Food and Drug Administration reported totally 32 deaths out of 629 trocar injuries, from 1993 to 1996 . Of the deaths, $81 \%$ of the deaths were due to the major vascular injuries and the remaining $19 \%$ were the result of bowel injuries.

Most of the trocar injuries are nonfatal vascular injuries followed by nonfatal visceral injuries emerging as bowel or abdominal wall hematomas ${ }^{[34]}$. Among the vascular injuries, the most commonly injured vessels are the aorta, inferior vena cava, iliac vessels and epigastric vessels (due to lateral trocars) ${ }^{[35,36]}$.

In RARP, vascular injuries most frequently occur during the trocar insertion and lymphadenectomy ${ }^{[37]}$. They can also occur during neurovascular bundle dissection, and during the handling of the dorsal vein complex or the lateral pedicles. Bipolar coagulation and clipping are very effective to control bleeding. If the bleeding persists, the vessel should be tied with straight needle suturing through the abdominal wall ${ }^{[38]}$.

During lymphadenectomy, direct contact should be avoided between the energy-based instruments and vessels. Some reports exist about the failure of the insulation of laparoscopic instruments that results in burning by the direct electrocautery electricity passage through the vessels ${ }^{[27]}$. A direct cut to the iliac vessels may also occur. Compression is the first step of the treatment. Then pneumoperitoneum should be increased to $20 \mathrm{mmHg}$. In venous injuries, this action would stop the bleeding and allow repair. In arterial bleedings, rolled gauze sponges should be utilized as a tamponade to stop the bleeding ${ }^{[39]}$.

\section{Patient positioning and compartment syndrome}

\section{Patient positioning}

Proper patient positioning has a critical role in any surgical procedure. It is necessary for adequate exposure and access, and also reduces the iatrogenic injuries as compartment syndrome and peripheral nerve damage.

Intraoperative physiologic changes include increased intraocular pressure, central venous pressure, intracranial and pulmonary venous pressure, and decreased functional residual capacity and pulmonary compliance. Lung functions may be compromised prominently if the patient is too tightly taped to the table ${ }^{[40]}$. Prolonged Trendelenburg position may result in pooling of the venous blood in upper extremities. Subsequently, head and neck edema may be seen and also re-intubation may be required due to laryngeal edema and posterior ischemic optic neuropathy (PION) even after minimally invasive radical prostatectomy ${ }^{[41,42]}$. Orbital stretching or direct compression from facedown prone positioning may also cause permanent vision loss. 
The absolute mechanism of PION is unknown, but might be the result of optic nerve ischemia. Multiple factors have been proposed as underlying mechanisms of PION but the PION cases after open radical prostatectomy is found to be associated with prolonged hypotension as the result of excessive blood loss ${ }^{[43,44]}$. Urologists should immediately consult such patients to ophthalmologists.

Secondary corneal abrasions may be seen due to positional eye edema related with Trendelenburg positioning. Foam-based safety goggles should be placed over the patient's eyes before the operation and should stay throughout 90 min postoperatively in the recovery room, until the patient is oriented enough not to rub his eyes. The use of these goggles presents significant decrease in corneal abrasion rates ${ }^{[45]}$.

Shoulder braces are used commonly to prevent cephalad migration but may lead to brachial plexus injuries if apply excessive pressure on the upper roots and trunks of the brachial plexus ${ }^{[46]}$.

The surgeon should be cautious about the potential for trauma during the docking of the robot and set the arms to minimize the risk. Besides, increased surgeon comfort may protract the operative time, thus increase the risk of neuropraxia and compartment syndrome ${ }^{[41,42]}$.

\section{Compartment syndrome}

Lower limb compartment syndrome (LLCS) is a serious complication occurs in RARP but its incidence is low. In a multicenter study, LLCS was developed at 9 cases with the incidence of $0.29 \%$. The prevalent factors were console time $>4 \mathrm{~h}$ in 8 cases, to be at early steps of learning curve (less than 20 cases) in 3 cases, obesity (body mass index $>30 \mathrm{~kg} / \mathrm{m}^{2}$ ) in 5 cases, peripheral vascular disease in $2 / 9$ cases and incorrect positioning in 1 case. Fasciotomy was required in 7 cases, and primarily closed at 5 patients. However, 2 patients required graft to cover the skin defect and were treated with intravenous (i.v.) fluids and analgesia. No amputations and/or deaths were reported.

Correct positioning of the patient is essential to prevent LLCS. Legs should be replaced to the appropriate position just after the robot undocked. Decompressive fasciotomy outcomes become poorer by the time passing. Urologist should be cautious about patients with leg pain in recovery period and early refer the suspected cases to a specialist. During the learning curve, careful case selection and active mentorship is recommended to keep console time $<4 \mathrm{~h}^{[47]}$.

\section{Obturator nerve injury}

Obturator nerve injury (ONI) is a rarely seen complication of RARP. Besides, the most common nerve injury during RARP is the obturator nerve injury with $0.4 \%$ frequency ${ }^{[48,49]}$. The injury may be in the form of stretching, entrapment by clips, transection or burning of the nerve during PLND. Even though ONI is rare, it is essential to take precaution and recognize promptly for immediate repair to avoid the significant morbidities such as loss of motor and sensory adductor functions. A full knowledge of pelvic anatomy and careful dissection are essential for both prevention and repair of the ONI.

In prevention, optimal visualization of the nerve should be provided. Obturator lymph nodes should be pulled medially for observation of the nerve. Clips must be placed carefully and parallel to the nerve. To prevent electrofulguration effects, we should better prefer bipolar cautery. In case of a total transection, if recognized during the RARP procedure, the transected nerve edges should be sutured to prevent persistant disfunction and ensuing atrophy of the adductor muscles ${ }^{[50]}$.

Ghazi et al ${ }^{[51]}$ reported their complication rates as 3 of total 1503 RARP cases in terms of ONI. Inadvertent clipping was hold responsible for the complication. They recognized and removed the clips intraoperatively and they observed the patients postoperatively. 
Gözen et al. ${ }^{[52]}$ reported 2 cases with obturator nerve transection in their total 1027 RARP cases. All injuries were detected at the proximal part of the obturator nerve. They recognized the both cases during the RARP and immediately removed the clips by dissectors. They repaired the transected nerve edges with 6/0 polypropylene suture. One of the ONI cases needed to administer a neurotropic drug, and the other one also received physiotherapy besides the neurotropic drug. In a mean follow-up period of 19 months, they observed a successful recovery in the both cases ${ }^{[52]}$.

\section{Lymphocele}

A lymphocele is lymphatic fluid collection as a consequence of surgical dissection and insufficient closure of afferent lymphatic vessels. Lymphocele is the most frequent complication after PLND. Lymphoceles are generally subclinical. Pelvic pressure, urinary frequency, deep venous thrombosis, ileus, infection and edema are the common symptoms.

In PCa cases, PLND is the most effective procedure for accurate cancer staging and removes all tumor deposits. Intraoperative complications related with PLND include ureteral, obturator nerve (sensory/motor neuropraxia) and major vascular injury.

Its incidence changes from $0 \%$ to $8 \%$ according to different reports. In a subgroup analysis, Davis et al. ${ }^{[33]}$ found the rate of the symptomatic lymphoceles as $19 \%$ after extraperitoneal RARP, but $0 \%$ after transperitoneal RARP. The incidence of the PLND associated grade 3 and grade 4 complications during RARP vary from $0 \%$ to $5 \%$. Only PLND related complications are rare. Any vascular injury necessitating transfusion or conversion to open surgery related with PLND were not reported yet ${ }^{[53]}$. Van der Poel et al. ${ }^{[54]}$ observed no significant difference among the complication incidences between men undergoing PLND or not.

In a recent report, Briganti et al.$^{[55]}$ revealed that the rate of lymphocele was significantly increased (10.3\%) in extended PLND as compared with limited PLND (4.6\%). Accordingly, Naselli et al. ${ }^{[56]}$ reported that the number of LNs retrieved was an independent and statistically significant predictor of the symptomatic lymphocele occurrence.

Keskin et al ${ }^{[57]}$ reported the lymphocele rate as $9 \%$ in 521 patients RARP series. The number of the symptomatic lymphoceles was 13 . All lymphocele cases were detected by ultrasound at the routine followup at the end of the postoperative 1st month. Lymphocele was unilateral in 43 patients and bilateral in 3 . At the end of the postoperative 6th month, ultrasonographic findings regressed in only 11 of 46 cases (24\%).

Percutaneous external drainage was performed to 7 patients. As the history of the patients assessed, 5 of the 7 patients who presented an infected lymphocele were the cases with diabetes mellitus. A patient who was diagnosed before the routine first month follow-up was also diabetic, and presented new-onset bilateral leg edema, urinary incontinence and fever at the postoperative 3rd week. Bilateral lymphoceles and deep venous thrombosis were detected by ultrasonography and immediately treated with antibiotics, bilateral drainage, bed rest and high dose of low molecular weight heparin. The symptomatic lymphocele incidence was as low as $2.5 \%$ in this study. Infection was the most common sign. Hydrocele, leg edema, incontinence, deep venous thrombosis and superficial phlebitis were rarely observed ${ }^{[58]}$.

Taniguchi et al. ${ }^{[59]}$ presented a patient with delayed lymphocele infection after RARP and PLND in a recent case report. The patient who did not have known risk factors for lymphocele, applied with the complaint of fever and fatigue after 6 months from the operation. Pelvic ultrasonography and computed tomography (CT) showed an $80 \mathrm{~mm}$ cystic lesion leading to displacement of the urinary bladder. Blood markers of infection were increased. Fluid collection was drained and drainage tube was placed. Methicillin-susceptible 
S. aureus were isolated and empiric antibiotic treatment was replaced by cefazolin $4 \mathrm{~g} /$ day. At the 7 th day, the drainage tube was removed due to reduction in lymphocele size. Two months after, CT showed no recurrence ${ }^{[59]}$.

\section{Thromboembolism}

Thromboembolism includes deep venous thrombosis (DVT) and pulmonary thromboembolism (PTE). It is a serious complication with a low incidence as $<1 \%{ }^{[60]}$. Generally, redisposing factors are venous stasis, vascular damage and hypercoagulability. Intermittent compressive devices (ICDs) or low-molecular-weight heparin (LMWH) should be used in prophylaxis. ICDs reduce only the DVT rate, however LMWH reduces both the DVT and PTE rates significantly ${ }^{[61]}$.

\section{Trochar site hernia}

Trocar site hernia (TSH) is a serious uncommon complication and mostly requires surgical intervention. The overall incidence ranges from $0 \%$ to $5.2 \%^{\left[{ }^{[62]}\right]}$. TSH was reported at $5 \mathrm{~mm}$ or even smaller port sites ${ }^{[63]}$. TSH may also develop at the complete fascial closure sites, even though fascial closure prevents TSH $^{[64]}$. TSH may also develop despite the use of bladeless and radially dilating trocars that are designed specially to decrease the fascial and muscular defect size ${ }^{[65]}$. In facts, nearly 4 of the reported cases were shown as related with the high prevalence of the procedure RARP ${ }^{[66-68]}$.

Predisposing situations for post-operative TSH development should be evaluated according to underlying mechanisms. Technical and surgical factors include the size of the trocar site fascial defect, use of the cutting or non-bladed trocars, time period of the surgery, port locations (midline or paramedian), excessive manipulation at the port site leading to stretching of the fascia layers, specimen retrieval, angle of the trocar insertion and fascial closure at the end of the procedure. Patient factors include obesity, some postoperative factors such as cough or chronic constipation resulting in increased intraabdominal pressure, and factors affecting wound healing such as chemotherapy, diabetes mellitus, infection, malnutrition or smoking ${ }^{[69]}$.

Tsu et al. ${ }^{[70]}$ published a TSH case report in 2013. Patient has the bilateral open inguinal herniography history with recurrence at the left side requiring subsequent laparoscopic hernioplasty. RARP with bilateral pelvic lymphadenectomy was performed by the 6-port trans-peritoneal approach described by Pick et al. ${ }^{[71]}$. The $12-\mathrm{mm}$ periumbilical port site used for the camera was enlarged at the level of specimen retrieval. This enlarged port site and the $12-\mathrm{mm}$ assistant port site were closed with polydiaxanone at the fascial level. A 5-mm assistant port and three 8-mm robotic arm ports were closed at the skin level only. On the postoperative 4th day, patient had abdominal pain, distension and notable tender bulge near the 8 -mm robotic arm port scar. Abdominal radiographs revealed ileus and CT showed that the bowel herniated through a fascial defect at the left 8 -mm port site. Mini laparotomy was performed over the defect. In exploration, a loop of small bowel was found as trapped between the external and internal oblique muscles. The bowel loops were returned to the peritoneal cavity. Fascial layers of the laparotomy were closed separately with polydiaxanone. The patient represented an uneventful recovery ${ }^{[70]}$.

In classical laparoscopy, the fascial port sites smaller than $10 \mathrm{~mm}$ may not be closed since the technical difficulties. However, the robotic arms generate a larger torque in the abdominal wall ${ }^{[6]]}$. This information explains why TSH occurs after RARP. Seamon et al. ${ }^{[66]}$ advised inserting surgical plugs into the $8 \mathrm{~mm}$ port site fascial defects when fascia is not closed. To avoid an excessively large fascial defect and enlarged preperitoneal space, Spaliviero et al. ${ }^{[67]}$ recommended inserting the $8 \mathrm{~mm}$ port at a $60^{\circ}-90^{\circ}$ angle and closing the fascial layers in patients with risk factors for hernia development.

Lim et al. ${ }^{[69]}$ reported a small bowel obstruction case due to an interparietal trocar site hernia after RARP. They recommended that $8 \mathrm{~mm}$ robotic trocar sites, associated with a large peritoneal defect, should be carefully closed at the end of surgery. 
Chiong et al ${ }^{[65]}$ reported the incidence of TSH as $0.66 \%$, all occurring at sites of $12 \mathrm{~mm}$ trocars, even though with the use of bladeless, blunt trocars. Furthermore, they suggested to insert the trocar at least $40^{\circ}-60^{\circ}$ to the abdominal wall to reduce the TSH occurrence risk ${ }^{[6,72]}$.

Routine fascial closure is not recommended as the TSH incidence is rare in $8 \mathrm{~mm}$ robotic trocar sites. Instead, removal of ports under direct visualization is recommended at the end of the procedure to make sure that bowel segments are not unawarely pulled into the port sites during the port removal and to assess the degree of peritoneal defect ${ }^{[69]}$.

\section{Vesicourethral anastomotic strictures}

Vesicourethral anastomotic strictures (VUAS) are fibrotic narrowing of the vesicourethral anastomosis. The incidence is less than $1.4 \%$ in RARC series ${ }^{[73,74]}$. The mostly seen comorbid conditions related with anastomotic stenosis are older age, cigarette smoking, hypertension, coronaryartery disease, obesity, prior bladder surgery, diabetes mellitus that affect vascular health, increase the tissue ischemia and result in poor healing. Anastomotic urine leakage, foreign body in urinary bladder, increased estimated blood loss and increased operative time that result in poor anastomotic mucosal apposition were also found as related with VUAS ${ }^{[75]}$.

VUAS generally becomes symptomatic within 6 months following prostatectomy and the duration rarely prolongs up to 24 months $^{[76]}$. Complaints related with voiding are primarily in obstructive pattern such as straining to void, weak stream, incomplete bladder emptying and hesitancy. Urinary retention and recurrent urinary tract infections may also indicate VUAS. Besides, the patients with radiotheraphy history often complain of urinary urgency and frequency, and dysuria.

Sandhu et al ${ }^{[77]}$ found VUAS rate as $4 \%(n=198)$ in overall 4500 radical prostatectomy cases performed at Memorial Sloan-Kettering hospital. They detected the VUAS cases at an average of 3.5 months after prostatectomy. They were also found that the VUAS risk increased 10-folds in open procedures compared with minimal invasive methods ${ }^{[77]}$.

In the management of VUAS, no consensus exists. Conservative management and open or minimally invasive surgical procedures may be a choice in the treatment plan. Patient preference is also important in decision. First-line management includes various endoscopic procedures, and complex reconstructive procedures may be applied in case of failure.

\section{High-risk disease}

D'Amico et al. ${ }^{[78]}$ defined the high-risk disease as prostate-specific antigen level $\geq 20 \mathrm{ng} / \mathrm{mL}$, preoperative Gleason grade $\geq 8$ or clinical stage $\geq$ T2c by considering oncologic outcomes. Srougi et al. ${ }^{[79]}$ performed RARP in 199 high-risk PCa cases and found their complication rate as $12.1 \%$ (4.5\% as major complications). Jayram et al.$^{[80]}$ performed RARP in $148 \mathrm{PCa}$ cases diagnosed as high-risk disease. They reported excellent complication rates as $0.6 \%$ in terms of minor complications (Clavien 1-2; urethral stricture) and $3.4 \%$ in terms of major complications (Clavien 3; lymphocele, hematoma/clot retantion and incisional hernia).

\section{CONCLUSION}

RARP can be routinely performed with a relatively low risk of complications. Surgical experience, cancer characteristics and clinical patient characteristics determine the risk of complications. Increased perioperative complications rates are significantly associated with low surgeon volume, low hospital volume and extended lymph node dissection. True patients selection, proper positioning, mentorship in the learning curve and avoiding prolonged procedures are important points in preventing RARP- 
related complications. Nevertheless RARP has low complication rates, it should be kept in mind that the complications may be devastating if not noticed. Thus surgeons should pay full attention in prevention and early management of complications.

\section{DECLARATIONS}

\section{Authors' contributions}

Manuscript preparation, literature search and data collection: Koc E

Study design and definition of intellectual content: Canda AE

\section{Financial support and sponsorship}

None.

\section{Conflicts of interest}

There are no conflicts of interest.

\section{Patient consent}

Not applicable.

\section{Ethics approval}

Not applicable.

\section{Copyright}

(c) The Author(s) 2018.

\section{REFERENCES}

1. Clavien PA, Barkun J, de Oliveira ML, Vauthey JN, Dindo D, Schulick RD, de Santibañes E, Pekolj J, Slankamenac K, Bassi C, Graf R, Vonlanthen R, Padbury R, Cameron JL, Makuuchi M. The Clavien-Dindo classification of surgical complications: five-year experience. Ann Surg 2009;250:187-96.

2. Martin RC 2nd, Brennan MF, Jaques DP. Quality of complication reporting in the surgical literature. Ann Surg 2002;235:803-13.

3. Donat SM. Standards for surgical complication reporting in urologic oncology: time for change. Urology 2007;69:221-5.

4. Sotelo R, Nunez Bragayrac LA, Machuca V, Garza Cortes RR, Azhar RA. Avoiding and managing vascular injury during robotic-assisted radical prostatectomy. Ther Adv Urol 2015;7:41-8.

5. Tewari A, Sooriakumaran P, Bloch DA, Seshadri-Kreaden U, Hebert AE, Wiklund P. Positive surgical margin and perioperative complication rates of primary surgical treatments for prostate cancer: a systematic review and meta-analysis comparing retropubic, laparoscopic, and robotic prostatectomy. Eur Urol 2012;62:1-15.

6. Novara G, Ficarra V, Rosen RC, Artibani W, Costello A, Eastham JA, Graefen M, Guazzoni G, Shariat SF, Stolzenburg JU, Van Poppel H, Zattoni F, Montorsi F, Mottrie A, Wilson TG. Systematic review and meta-analysis of perioperative outcomes and complications after robotassisted radical prostatectomy. Eur Urol 2012;62:431-52.

7. Shekarriz B, Upadhyay J, Wood DP. Intraoperative, perioperative, and long-term complications of radical prostatectomy. Urol Clin North Am 2001;28:639-53.

8. McLaren RH, Barrett DM, Zincke H. Rectal injury occurring at radical retropubic prostatectomy for prostate cancer: etiology and treatment. Urology 1993;42:401-5.

9. Novara G,Ficarra V, D'Elia C, Secco S, Cavalleri S, Artibani W. Prospective evaluation with standardized criteria for postoperative complications after robotic-assisted laparoscopic radical prostatectomy. Eur Urol 2010;57:363-70.

10. Wedmid A, Mendoza P, Sharma S, Hastings RL, Monahan KP, Walicki M, Ahlering TE, Porter J, Castle EP, Ahmed F, Engel JD, Frazier HA 2nd, Eun D, Lee DI. Rectal injury during robot-assisted radical prostatectomy: incidence and management. J Urol 2011;186:1928-33.

11. Hung CF, Yang CK, Cheng CL, Ou YC. Bowel complication during rabatic-assisted laparoscopic radical prostatectomy. Anticancer Res 2011;31:3497-501.

12. Bishoff JT, Allaf ME, Kirkels W, Moore RG, Kavoussi LR, Schroder F. Laparoscopic bowel injury: incidence and clinical presentation. $J$ Urol 1999;161:887-90.

13. Jacobsen A, Berg KD, Iversen P, Brasso K, Røder MA. Anastomotic complications after robot-assisted laparoscopic and open radical prostatectomy. Scand J Urol 2016;50:274-9.

14. Tyritzis, SI, Ioannis K, Constantinos AC. All you need to know about urethrovesical anastomotic urinary leakage following radical prostatectomy. J Urol 2012;188:369-76.

15. Ramsden AR, Chodak GW. Can leakage at the vesico-urethral anastomosis be predicted after radical retropubic prostatectomy? BJU Int 
2004;93:503-6.

16. Agarwal PK, Sammon J, Bhandari A, Dabaja A, Diaz M, Dusik-Fenton S, Satyanarayana R, Simone A, Trinh QD, Baize B, Menon M. Safety profile of robot-assisted radical prostatectomy: a standardized report of complicationsin 3317 patients. Eur Urol 2011;59:684-98.

17. Di Pierro GB, Grande P, Mordasini L, Danuser H, Mattei A. Robot-assisted radical prostatectomy in the setting of previous abdominal surgery: perioperative results, oncological and functional outcomes, and complications in a single surgeon's series. Int J Surg 2016;36:1706.

18. Tewari A, Sooriakumaran P, Bloch DA, Seshadri-Kreaden U, Hebert AE, Wiklund P. Positive surgical margin and perioperative complication rates of primary surgical treatments for prostate cancer: a systematic review and meta-analysis comparing retropubic, laparoscopic, and robotic prostatectomy. Eur Urol 2012;62:1-15.

19. Guillonneau B, Rozet F, Cathelineau X, Lay F, Barret E, Doublet JD, Baumert H, Vallancien G. Perioperative complications of laparoscopic radical prostatectomy: the Montsouris 3-year experience. J Urol 2002;167:51-6.

20. Sotelo RJ, Haese A, Machuca V, Medina L, Nuñez L, Santinelli F, Hernandez A, Kural AR, Mottrie A, Giedelman C, Mirandolino M, Palmer K, Abaza R, Ghavamian R, Shalhav A, Moinzadeh A, Patel V, Stifelman M, Tuerk I, Canes D. Safer surgery by learning from complications: a focus on robotic prostate surgery. Eur Urol 2016;69:334-44.

21. Zorn KC, Gofrit ON, Orvieto MA, Mikhail AA, Galocy RM, Shalhav AL, Zagaja GP. Da Vinci robot error and failure rates: single institution experience on a single three-arm robot unit of more than 700 consecutive robot-assisted laparoscopic radical prostatectomies. $J$ Endourol 2007;21:1341-4.

22. Hisasue S, Takahashi A, Kato R, Shimizu T, Masumori N, Itoh N, Tsukamoto T. Early and late complications of radical retropubic prostatectomy: experience in a single institution. Jpn J Clin Oncol 2004;34:274-9.

23. Augustin H, Hammerer P, Graefen M, Palisaar J, Noldus J, Fernandez S, Huland H. Intraoperative and perioperative morbidity of contemporary radical retropubic prostatectomy in a consecutive series of 1243 patients: results of a single center between 1999 and 2002. Eur Urol 2003;43:113-8.

24. Badani KK, Kaul S, Menon M. Evolution of robotic radical prostatectomy: assessment after 2766 procedures. Cancer 2007;110:1951-8.

25. Patel VR, Thaly R, Shah K. Robotic radical prostatectomy: outcomes of 500 cases. BJU Int 2007;99:1109-12.

26. Ahlering TE, Patel V, Lee DI, Skarecky DW. Multi institutional review of complications after robot-assisted laparoscopic prostatectomy (RLP). J Endourol 2006;20:8-11.

27. Lorenzo EI, Jeong W, Park S, Kim WT, Hong SJ, Rha KH. Iliac vein injury due to a damaged Hot Shears ${ }^{\mathrm{TM}}$ tip cover during robot assisted radical prostatectomy. Yonsei Med $J$ 2011;52:365-8.

28. Ahmed F, Rhee J, Sutherland D, Benjamin C, Engel J, Fraizer H. Surgical complications after robot-assisted laparoscopic radical prostatectomy: the initial 1000 cases stratified by the clavien classification system. $J$ Endourol 2012;26:135-9.

29. Patel VR, Palmer KJ, Coughlin G, Samavedi S. Robot-assisted laparoscopic radical prostatectomy: perioperative outcomes of 1500 cases. $J$ Endourol 2008;22:2299-305

30. Murphy DG, Kerger M, Crowe H, Peters JS, Costello AJ. Operative details and oncological and functional outcome of robotic-assisted laparoscopic radical prostatectomy: 400 cases with a minimum of 12 months follow-up. Eur Urol 2009;55:1358-16.

31. Fischer B, Engel N, Fehr JL, John H. Complications of robotic assisted radical prostatectomy. World J Urol 2008;26:595-602.

32. Tasci AI, Simsek A, Tugcu V, Bitkin A, Sonmezay E, Torer BD. Abdominal wall haemorrhage after robotic-assisted radical prostatectomy: is it a complication of robotic surgery? Actas Urol Esp 2013;37:634-9.

33. LarobinaM, Nottle P. Complete evidence regarding major vascular injuries during laparoscopic access. Surg Laparosc Endosc Percutan Tech 2005;15:119-23.

34. Bhoyrul S, Vierra MA, Nezhat CR, Krummel TM, Way LW. Trocar injuries in laparoscopic surgery. J Am Coll Surg 2001;192:677-83.

35. Castillo O, Peacock L, Vitagliano G, Pinto I, Portalier P. Laparoscopic repair of an iliac artery injury during radical cystoprostatectomy. Surg Laparosc Endosc Percutan Tech 2008;18:315-8.

36. Pereira Arias JG, Gamarra Quintanilla M, Leibar Tamayo A, Astobieta Odriozola A, Ibarluzea González G. Complications and incidences in our first 250 robotic radical prostatectomies. Actas Urol Esp 2010;34:428-39.

37. Zorn K, Katz M, Bernstein A, Shikanov S, Brendler C, Zagaja Z. Shalhav AL. Laparoscopy and robotics pelvic lymphadenectomy during robot-assisted radical prostatectomy: assessing nodal yield, perioperative outcomes, and complications. Urology 2009;74:296-302.

38. Stolzenburg JU, Rabenalt R, Do M, Lee B, Truss MC, McNeill A, Burchardt M, Jonas U, Liatsikos EN. Complications of endoscopic extraperitoneal radical prostatectomy (EERPE): prevention and management. World J Urol 2006;24:668-75.

39. Siqueira T, Kuo R, Gardner T, Paterson R, Stevens L, Lingeman JE, Koch MO, Shalhav AL. Major complications in 213 laparoscopic nephrectomy cases: the Indianapolis experience. $J$ Urol 2002;168:1361-5.

40. Gainsburg DM, Wax D, Reich DL, Carlucci JR, Samadi DB. Intraoperative management of robotic-assisted versus open radical prostatectomy. JSLS 2010;14:1-5.

41. Phong SV, Koh LK. Anaesthesia for robotic-assisted radical prostatectomy: considerations for laparoscopy in the Trendelenburg position. Anaesth Intensive Care 2007;35:281-5.

42. Weber ED, Colyer MH, Lesser RL, Subramanian PS. Posterior ischemic optic neuropathy after minimally invasive prostatectomy. $J$ Neuroophthalmol 2007;27:285-7.

43. Foroozan R. Shock-induced anterior ischemic optic neuropathy after radical prostatectomy. Clin Exp Ophthalmol 2004;32:438-9.

44. Williams GC, Lee AG, Adler HL, Coburn A, Rosas AL, Tang RA, Scardino PT. Bilateral anterior ischemic optic neuropathy and branch retinal artery occlusion after radical prostatectomy. J Urol 1999;162:1384-5.

45. Liss MA, Skarecky D, Morales B, Osann K, Eichel L, Ahlering TE. Preventing perioperative complications of robotic-assisted radical prostatectomy. Urology 2013;81:319-23.

46. Winfree CJ, Kline DG. Intraoperative positioning nerve injuries. Surg Neurol 2005;63:5-18.

47. Pridgeon S, Bishop CV, Adshead J. Lower limb compartment syndrome as a complication of robot-assisted radical prostatectomy: the UK 
experience. BJU Int 2013;112:485-8.

48. Nezhat FR, Chang-Jackson SC, Acholonu UC Jr, Vetere PF. Robotic-assisted laparoscopic transection and repair of an obturator nerve during pelvic lymphadenectomy for endometrial cancer. Obstet Gynecol 2012;119:462-4.

49. Rothmund R, Huebner M, Kraemer B, Liske B, Wallwiener D, Taran FA. Laparoscopic transection and immediate repair of obturator nerve during pelvic lymphadenectomy. J Minim Invasive Gynecol 2011;18:807-8.

50. Song MJ, Lee CW, Yoon JH, Hur SY. Transection of the obturator nerve by an electrosurgical instrument and its immediate repair during laparoscopic pelvic lymphadenectomy: a case report. Eur J Gynaecol Oncol 2014;35:167-9.

51. Ghazi A, Scosyrev E, Patel H, Messing EM, Joseph JV. Complications associated with extraperitoneal robot-assisted radical prostatectomy using the standardized Martin classification. Urology 2013;81:324-33.

52. Gözen AS, Aktoz T, Akin Y, Klein J, Rieker P, Rassweiler J. Is it possible to draw a risk map for obturator nerve injury during pelvic lymph node dissection? The Heilbronn experience and a review of the literature. J Laparoendosc Adv Surg Tech A 2015;25:826-32.

53. Davis JW, Shah JB, Achim M. Robot-assisted extended pelvic lymph node dissection at the time of radical prostatectomy: a video-based illustration of technique, results, and unmet patient selection needs. BJU Int 2011;108:993-8.

54. Van der Poel HG, de Blok W, Tillier C, van Muilekom E. Robot-assisted laparoscopic prostatectomy: nodal dissection results during the first 440 cases by two surgeons. $J$ Endourol 2012;26:1618-24.

55. Briganti A, Chun FK, Salonia A, Suardi N, Gallina A, Da Pozzo LF, Roscigno M, Zanni G, Valiquette L, Rigatti P, Montorsi F, Karakiewicz PI. Complications and other surgical outcomes associated with extended pelvic lymphadenectomy in men with localized prostate cancer. Eur Urol 2006;50:1006-13.

56. Naselli A, Andreatta R, Introini C, Fontana V, Puppo P. Predictors of symptomatic lymphocele after lymph node excision and radical prostatectomy. Urology 2010;75:630-5.

57. Keskin MS, Argun ÖB, Öbek C, Tufek I, Tuna MB, Mourmouris P, Erdoğan S, Kural AR. The incidence and sequela of lymphocele formation after robot-assisted extended pelvic lymph node dissection. BJU Int 2016;118:127-31.

58. Raheem OA, Bazzi WM, Parsons JK, Kane CJ. Management of pelvic lymphoceles following robot-assisted laparoscopic radical prostatectomy. Urol Ann 2012;4:111-4.

59. Taniguchi T, Takahashi Y, Taniguchi M, Yamada T, Ishida K. Delayed infection of a lymphocele following RARP in a patient with nonspecific symptoms. Case Rep Urol 2017;2017:3935082.

60. Tewari A, Sooriakumaran P, Bloch DA, Seshadri-Kreaden U, Hebert AE, Wiklund P. Positive surgical margin and perioperative complication rates of primary surgical treatments for prostate cancer: a systematic review and meta-analysis comparing retropubic, laparoscopic, and robotic prostatectomy. Eur Urol 2012;62:1-15.

61. Nicolaides AN, Breddin HK, Fareed J, Goldhaber S, Haas S, Hull R, Kalodiki E, Myers K, Samama M, Sasahara A. Prevention of venous thromboembolism. International consensus statement. $J$ Vasc Biol 2002;1:133-70.

62. Swank HA, Mulder IM, la Chapelle CF, Reitsma JB, Lange JF, Bemelman WA. Systematic review of trocar-site hernia. Br J Surg 2012;99:315-23.

63. Yamamoto M, Minikel L, Zaritsky E. Laparoscopic 5-mm trocar site herniation and literature review. JSLS 2011;15:122-6.

64. Tapscott AK, Steven SK, White S, Graves R, Kraft K, Casale P. Port-site complications after pediatric urologic robotic surgery. J Robot Surg 2009;3:187-90.

65. Chiong E, Hegarty PK, Davis JW, Kamat AM, Pisters LL, Matin SF. Port-site hernias occurring after the use of bladeless radially expanding trocars. Urology 2010;75:574-80.

66. Seamon LG, Backes F, Resnick K, Cohn DE. Robotic trocar site small bowel evisceration after gynecologic cancer surgery. Obstet Gynecol 2008;112:462-4.

67. Spaliviero M, Samara EN, Oguejiofor IK, DaVault RJ, Albrecht RM, Wong C. Trocar site spigelian-type hernia after robot-assisted laparoscopic prostatectomy. Urology 2009;73:3-5.

68. Fuller A, Fernandez A, Pautler SE. Incisional hernia after robot-assisted radical prostatectomy-predisposing factors in a prospective cohort of 250 cases. $J$ Endourol 2011;25:1021-4.

69. Lim SK, Kim KH, Shin TY, Hong SJ, Choi YD, Rha KH. A rare case of interparietal incisional hernia from $8 \mathrm{~mm}$ trocar site after robotassisted laparoscopic prostatectomy. Hernia 2014;18:911-3.

70. Tsu JH, Ng AT, Wong JK, Wong EM, Ho KL, Yiu MK. Trocar-site hernia at the 8-mm robotic port after robot-assisted laparoscopic prostatectomy: a case report and review of the literature. J Robot Surg 2014;8:89-91.

71. Pick DL, Lee DI, Skarecky DW, Ahlering TE. Anatomic guide for port placement for daVinci robotic radical prostatectomy. $J$ Endourol 2004; 18:572-5.

72. Mahmoud HY, Ustuner EH, Sozener U, Ozis SE, Turkcapar AG. Cannula site insertion technique prevents incisional hernia in laparoscopic fundoplication. Surg Laparosc Endosc Percutan Tech 2007;17:267-70.

73. Hu JC, Gu X, Lipsitz SR, Barry MJ, D'Amico AV, Weinberg AC, Keating NL. Comparative effectiveness of minimally invasive vs open radical prostatectomy. JAMA 2009;302:1557-64.

74. Carlsson S, Nilsson AE, Schumacher MC, Jonsson MN, Volz DS, Steineck G, Wiklund PN. Surgery-related complications in 1253 robotassisted and 485 open retropubic radical prostatectomies at the Karolinska University Hospital, Sweden. Urology 2010;75:1092-7.

75. Erickson BA, Meeks JJ, Roehl KA, Gonzalez CM, Catalona WJ. Bladder neck contracture after retropubic radical prostatectomy: incidence and risk factors from a large single-surgeon experience. BJU Int 2009; 104:1615-9.

76. Elliott SP, Meng MV, Elkin EP, McAninch JW, Duchane J, Carroll PR; CaPSURE Investigators. Incidence of urethral stricture after primary treatment for prostate cancer: data from CaPSURE. J Urol 2007;178:529-34.

77. Sandhu JS, Gotto GT, Herran LA, Scardino PT, Eastham JA, Rabbani F. Age, obesity, medical comorbidities and surgical technique are predictive of symptomatic anastomotic strictures after contemporary radical prostatectomy. J Urol 2011;185:2148-52.

78. D’Amico AV, Whittington R, Malkowicz SB, Schultz D, Blank K, Broderick GA, Tomaszewski JE, Renshaw AA, Kaplan I, Beard CJ, Wein 
A. Biochemical outcome after radical prostatectomy, external beam radiation therapy, or interstitial radiation therapy for clinically localized prostate cancer. JAMA 1998;280:969-74.

79. Srougi V, Tourinho-Barbosa RR, Nunes-Silva I, Baghdadi M, Garcia-Barreras S, Rembeyo G, Eiffel SS, Barret E, Rozet F, Galiano M, Sanchez-Salas R, Cathelineau X. The role of robot-assisted radical prostatectomy in high-risk prostate cancer. J Endourol 2017;31:229-37.

80. Jayram G, Decastro GJ, Large MC, Razmaria A, Zagaja GP, Shalhav AL, Brendler CB. Robotic radical prostatectomy in patients with highrisk disease: a review of short-term outcomes from a high-volume center. $J$ Endourol 2011;25:455-7. 